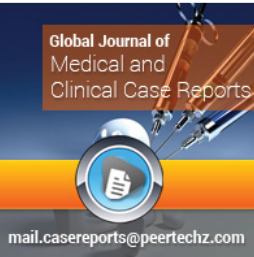

Clinical Group

\title{
Global Journal of Medical and Clinical Case Reports
}

\section{Naruemol Singha-Dong ${ }^{1 *}$ and April Bigelow ${ }^{2}$}

'Institute of Nursing, Suranaree University of Technology, Thailand

¿University of Michigan School of Nursing, USA

Dates: Received: 03 June, 2017; Accepted: 20 June, 2017; Published: 21 June, 2017

\section{*Corresponding author: Naruemol Singha-Dong,} Assistant Professor, Research Department Institute of Nursing, Suranaree University of Technology, University in Nakhon Ratchasima, Thailand, Tel: 66-44223-514; 66-89-716-5315; Fax: 66-44-223-506; E-mail: naruemol@g.sut.ac.th; naruemol@gmail.com

Keywords: Stroke specific genogram; Stroke risk; Community-based intervention; Family health; Community nursing

https://www.peertechz.com

\section{Case Report}

SUT Stroke Specific Genogram: Application of Genogram on Screening for Individual at Risks of Stroke in

\section{Rural Thai Community}

\section{Abstract}

Background: Non-communicable diseases including cardiovascular disease, hypertension, hyperlipidemia, and stroke are on the rise throughout the world. Further, there is a large proportion of individuals that have hyperlipidemia and hypertension that is not diagnosed, treated or controlled in low and middle income countries (LMICs). Notably, Asian countries including Thailand, have higher rates of mortality from stroke than from coronary heart disease. Despite several calls to action, there has been a lack of implementation of cardiovascular diseases prevention programs in LMICs largely due to insufficient investment in prevention efforts. One approach to combat these difficulties is to create a program or method aimed at early identification of those at risk for stroke. The purpose of this paper is to describe the use of a community stroke-risk focused genogram as a tool for identification of individuals in need of intervention and as a guide for the creation of educational prevention programs.

Methods: The study was conducted in a rural village of Pakthongchai district, an area that has consistently had high prevalence of hypertension, rising prevalence of stroke, and access of care issues. The Stroke Specific Genogram (SSG) tool was adapted from a pictorial standard genogram with additional narratives to give a visual representation of each participant's health history, record the history elicited, and identify actual problems and health risks based on elicited information. Stoke risk behaviors and current illness (es) were included in the SSG. Those behaviors included diet, hypertension prevention and control, stress management, smoking, and use of over the counter and prescription medications.

Results: The total number of family members was 78 , comprising of 37 males and 35 females. Level of education of most family members was four years and lower. Mr. S, the stroke index case, was shown in the second generation of the SSG. Causes of death of this family were hypertension, stroke, scleroderma, dengue hemorrhagic fever, typhoid fever, gun fire incident, and road accident, respectively. Of all 72 observed members, five members were known to have stroke with two deaths from stroke. One additional family member was recovering from stroke and immobile. From five generations, stroke risk factors were observed in all except one, the fifth generation.

Conclusions and Recommendations: The SSG was able to identify stroke risk of the case family and suggests need for further investigation on a broader level. There were no risks identified in the fourth generation which we propose is due to the young age and minimal exposure at this time. Therefore, programs aimed at prevention are warranted. The SSG identified individuals at risk for stroke allowing nurses to focus attention on those most at risk and to implement proactive assessment, screening, and educational programs. The Stroke Specific Genogram can easily be incorporated into all aspects of community health nursing practice, from assessment for case finding to planning and implementing disease management strategies.

\section{Introduction}

Chronic non-communicable diseases (NCD) such as heart disease, stroke, cancer, chronic respiratory diseases, hypertension, and diabetes mellitus are the most significant causes of death globally where $80 \%$ of chronic disease mortality occurs in low and middle income countries (LMIC) [1,2]. In recent decades, cardiovascular diseases (CVD) have become a leading cause of death in Asia, particularly in the SouthEast Asian region [3]. The World Health Organization (WHO) 
predicts nearly half of the 89 million NCD-related premature deaths projected will occur in the South East Asian region over the next 10 years $[1,4]$.

Similar to other South-East Asian countries, Thai Ministry of Public Health reported that chronic NCDs represent the largest cause of mortality in the Thai population in 2011. There is strong evidence that the burden of chronic disease is rapidly growing. In addition to premature deaths, NCDs play a role in family stress and relationships, quality of life, health care costs, and decreased productivity [5]. It is estimated that in the South-East Asian region, even a two percent annual reduction in deaths due to NCD could save more than eight million lives over the next 10 years [6]. Thus, efforts aimed at the overall prevention of NCDs warrant further development and exploration.

In the United States, NCD prevention efforts are focused on modifiable risk factors, such as diet, exercise, smoking, and alcohol intake. Education is provided to patients through points of contact in the healthcare system (e.g. preventative yearly screenings and visits) and local and national campaigns and initiatives. In rural Thailand, however, patients are not routinely screened annually and have limited points of contact with providers within the health care system further underscoring the need for prevention efforts and access to local educational sessions. Local sub-district health promotion hospitals are well positioned to deliver educational sessions to rural Thai villagers, but often lack resources, materials, and validated programs.

Further, there is a large proportion of individuals that have hyperlipidemia and/or hypertension that is not diagnosed, treated, or controlled in both Thailand and LMICs [7]. According to Howteerakul, Suqannapong, Sittilerd, \& Rawdaree [8], lifestyle programs are needed in Thailand to prevent hypertension: one of the largest risk factors for stroke. Notably, Asian countries including Thailand have higher rates of mortality from stroke than from coronary heart disease (CHD) [9]. Despite several calls to action, there has been a lack of implementation of CVD prevention programs in LMICs largely due to insufficient investment in CVD prevention efforts [10]. One approach to combat these difficulties is to create a program or method aimed at early identification of those at risk for stroke.

\section{Potential family influences on stroke}

Family members share genes, behaviors, lifestyles, and environments that can influence their health and their risk for disease [11]. Even though genetics is a non-modifiable risk factor of stroke, family can influence intentions to reduce risk and have the ability to support prevention [12]. Furthermore, the family, community, and immediate environment have an influence on the perceived support of a patient in making necessary lifestyle changes to decrease overall stroke risk. Those patients who have a stronger support system in place have a better chance of a positive outcome despite increased risk [13].

\section{Family case}

During a community clinical rotation in rural Thailand, American and Thai nursing students were introduced to their first patient who had just suffered a stroke. He was discharged from the hospital to the care of his family, however his condition deteriorated rapidly. During the students' time at the home they focused on family assessment and community assessment to determine any potential risk factors for this patient and family. Upon further investigation, close relatives revealed that other family members experienced stoke and only some of them survived. Ultimately, the patient died during the early part of the clinical rotation. Despite this unfortunate circumstance the patient's death motivated the students, the family, and the community to mobilize against stroke and identify potential risk factors. Thus, our team proposed to conduct stroke risk assessment and facilitate effective prevention with the remaining family and community members to address this NCD. The SUT Stroke Specific Genogram (SSG) was designed to be used as an initial assessment tool to assist in prevention and guiding education and management efforts of NCD and stroke.

\section{Genogram and SUT Stroke specific genogram}

Understanding family relationships and dynamics is an important facet of need identification, nursing management, care delivery especially therapeutic education and psychosocial support. Many of the risk factors for stroke are modifiable and community health nurses are in unique position to impact this major health problem because of their access to individuals, families, and groups. Genograms have been used to provide effective initial family assessment [14]. Further, genograms have been adapted into a number of health care aspects including systemic family therapy such as infant breastfeeding [15], gastroenterology [16], and palliative care [17]. Symbols are used to represent family structure, relationship nature, gender, age, and life status [15]. Evidence shows that genograms have good inter-interviewer reliability, with different interviewers eliciting almost identical information from participants [18].

As part of community nursing program at Suranaree University of Technology (SUT), Thailand, genograms have been used as a family and community assessment tool for family with maximum number of relatives living in a village as well as family with ill individuals at initial home visit. Life status and cause of death of deceased family members were recorded. SUT genograms record information about families over a five generation period and offer the opportunity to explore family history and their stories over time [19]. Genograms use pictorial representations of information showing family structure, characteristics, supportive or conflicting relationships, important life events across generations, and patterns of health and wellbeing over time. The graphic representation eases understanding of complex information among practitioners and health volunteers and facilitates discussions regarding potential relationships and health. Moreover, it helps affected families to depict and visually identify specific family risks and health problems making it easier to motivate health and behavior change. 
The SSG was adapted from a pictorial SUT standard genogram with additional narratives to give a visual representation of each participant's health history, record the history elicited, and identify actual problems and health risks based on elicited client information. This tool was developed as part of the SUT's integrated education and community service program to reduce disparity in rural Thai villages. Stoke risk behaviors and current illness (es) were included in the SSG. Those behaviors include diet, hypertension prevention and control, stress management, smoking, and use of over the counter and prescription medications.

\section{Objective}

This article describes the implementation of the SSG to identify individuals, families, and groups at risk for stroke, their relationships, and evaluates the usefulness of the genogram and its capacity to serve as an aid to better understand family structure and dynamics and implement targeted nursing interventions surrounding stroke and NCD.

\section{Methods}

\section{Setting}

The study was conducted in a rural village of Pakthongchai district, an area that has consistently had high prevalence of hypertension, rising prevalence of stroke, and access of care issues. According to community assessment, most village residents have a low educational level [20].

\section{Data collection method}

Family A was contacted through lay health volunteers and the local primary care unit to be informed about and recruited to the study. As the family is well aware of stroke severity, members generously accepted invitation to participate in data collection. Data were obtained using a semi-structured interview and group discussion at their house.

\section{Ethical consideration}

The family leaders invited family members to participate so that risk could be assessed and effective interventions could be facilitated. All participants were informed and consent was taken. Personal data of participants were processed with confidentiality. This study is part of a study surrounding NCD and prevention approved by SUT Institutional Review Board.

Conducted in 2015, participants included 2 family members and 5 relatives of a patient who died from stroke. The genogram was used to record relevant demographic and family information to complement the collection and interpretation of data. The SSG was completed using following steps: mapping family structure; recording family information such as dates of birth and death, dates of significant events, occupations; delineating family relationships including recording strong family bonds or conflicts; and adding medical history, health behaviors, and cultural background. At each stage, symbols were used to represent the data. For SSG, the genogram was adapted and new symbols were developed, as seen in figure 1.

In this case, the SSG assisted family members to explore their health risks, identify challenges and sources of support and build a relationship with the interviewer. Group discussion

\begin{tabular}{|c|l|c|l|}
\hline & $=$ Male & & $=$ Male with illness \\
\hline & $=$ Female & & $=$ Female with illness \\
\hline & $=$ Marriage & & $=$ Deceased male \\
\hline & $=$ Marriage with child/ children & Deceased female \\
\hline HTN & $=$ Divorce & number & $=$ Year of age \\
\hline Na & $=$ Consume sodium $>2400 \mathrm{mg} /$ day & Gen & $=$ Seneratension \\
\hline Dys & $=$ Dyslipidemia & DM & $=$ Diabetes \\
\hline Letter beneath dark box = cause of death & Dengue & $\begin{array}{l}\text { = Dengue Hemorrhagic } \\
\text { fever }\end{array}$ \\
\hline Letter beneath light box = cause of illness & SLE & $\begin{array}{l}\text { = Systemic Lupus } \\
\text { Erythematosus }\end{array}$ \\
\hline
\end{tabular}


allowed members help others recall family structure and discuss health history. Those who were identified as having stroke risk were administered further screening using physical assessment, $\mathrm{ABCD} 2$ algorithm for stroke risk following a transient ischemic attack (TIA) [21], and National Institute of Health (NIH) stroke scale [22], as needed either in the home during a student visit or in the clinic setting after scheduling an appointment.

Culturally, in Thailand, relatives come for funeral rituals and stay until two days after cremation for religious activities and to support the family. Thus, family members and relatives with identifiable risks were requested to meet for future investigation a day after cremation in order to allow broader relative attendants. Nursing students provided health education on stroke, presented genogram data and family and individual risk information to the extended family. Physical examinations were then performed and findings were recorded.

\section{Analysis}

The genograms assisted in maintaining the idiographic focus, providing context to the family stroke situation. The stories elicited were analyzed using context analysis. Stroke risk probability is estimated based on standard stroke guideline. Data were summarized using descriptive statistics. Paired t-tests were used to evaluate outcomes at four weeks after interventions.

\section{Results}

The total number of family members was 78 , comprising of 37 males and 35 females. Level of education of most family members was four years and lower. Mr. S, the stroke index case, was shown in the second generation of the SSG (Figure 2). Causes of death of this family were hypertension, stroke, road accident, scleroderma, dengue hemorrhagic fever, typhoid fever, and gun fire incident, respectively. Of all 72 observed members, five members were known to have stroke with two deaths from stroke. One additional family member was recovering from stroke and immobile. From five generations, stroke risk factors were observed in all except one, the fifth generation.

The family had many identifiable chronic NCDs present. Hypertension was the most frequently found underlying disease among participants followed by being at risk of hypertension. Other factors included typez diabetes, chronic obstructive pulmonary diseases (COPD), blindness, and systemic lupus erythematosus (SLE). Notable disability included blindness and aphasia. Figure 3 depicts illness and health risks among family members.

Behavioral risk factors included high sodium consumption, smoking and alcohol use, consumption of a diet high in uric acid, inefficient stress management and coping mechanisms, and occasionally steroid use. Risk factors found in similar proportion included being at risk of stroke, being a post-stroke patient, having both hypertension and typez diabetes, and being at risk for cardiovascular diseases.

\section{Health status of current family members}

According to the SSG of this family, individuals with stoke risk identified by verbal screening were managed to

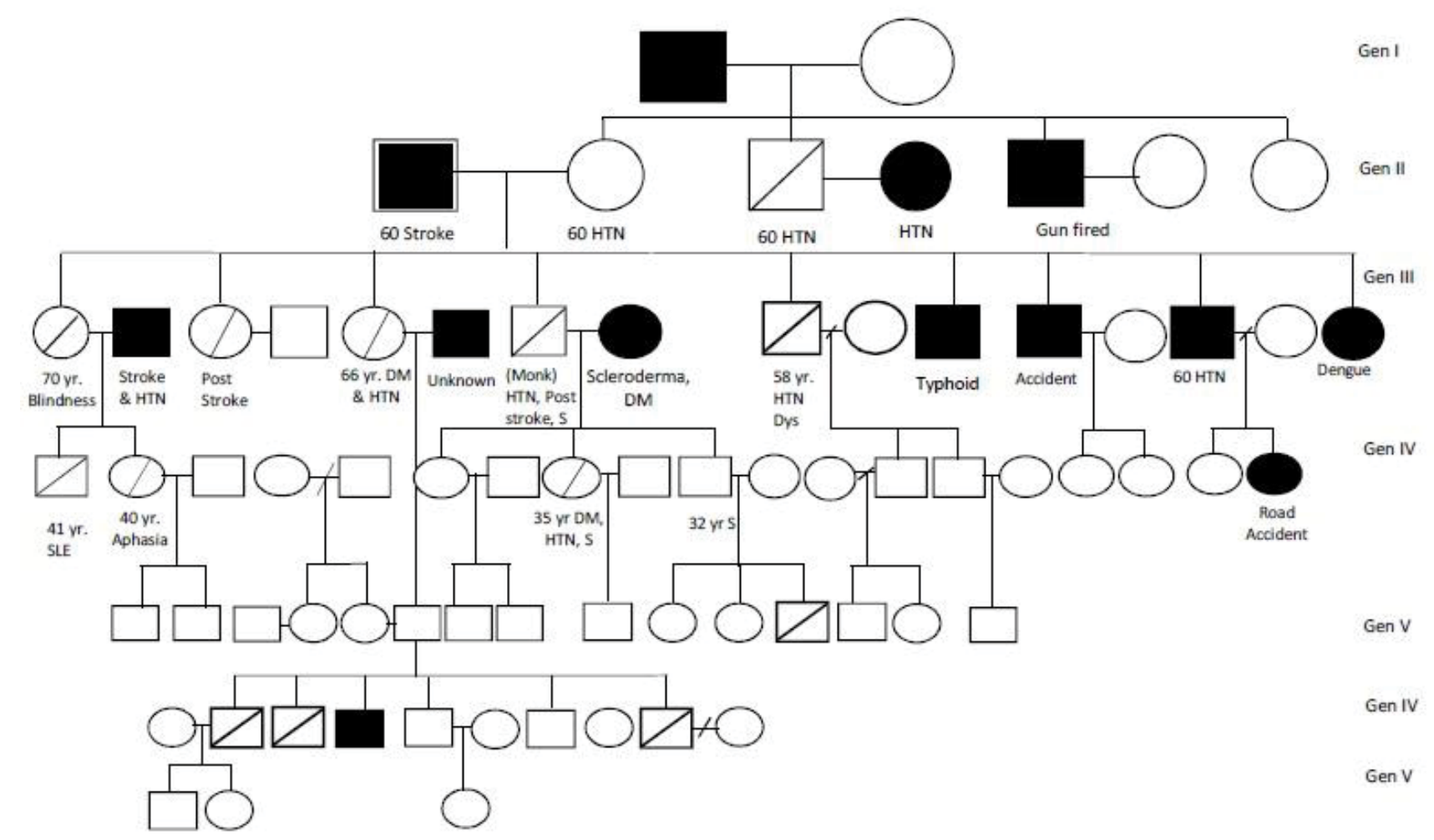

Figure 2: Family Stroke Specific Genogram. 
have appropriate investigation. Illness of living members in 2015 included hypertension (5.04\%), hypertension with DM $(2.16 \%)$, past stroke $(2.16 \%)$, disability $(1.44 \%)$, SLE $(0.72 \%)$ and valvular heart disease $(0.72 \%)$. Greater ratio of adult family members had dyslipidemia, moderate level of stress, and other chronic NCDs; those of which are significant risk of stroke. More importantly, the majority of family members, including children, had an unhealthy lifestyle.

\section{Nursing management: Individual and group based inter- ventions.}

Individuals with identifiable health problems and stroke risks were approached to deliver comprehensive interventions at home, the temple, and a primary care clinic by our community provider team. The team included nursing faculty, community nursing students, nurses of local clinic, and lay health volunteers. Seven members, including some relatives who lived elsewhere, participated in comprehensive interventions. Interventions and mode of delivery were presented in table 1.

Most interventions were provided in a group-based session. Family and relatives assist by holding each other accountable for sustainable behavior changes, especially for hypertension control. Continuing care and monitoring was done in a nuclear family manner. Referrals for those who live outside village were made as needed.

Every family member who was 15 years old and over received group-based stroke related education. Mean knowledge scores increased from 56 to 89 (Figure 4). T-test confirmed that participants had significant increases in stroke related knowledge $(\mathrm{t}=-9.9, \mathrm{p}<.001)$.

\section{Nursing and patient outcomes}

At the fourth week after initial interventions, three fourths of those at risk had significant improvement in behavioral and clinical outcomes and were able to reduce stroke risks. When compared with pre-intervention, series1, individuals who received interventions had lower level of blood pressure. However, they were fluctuating at the fifth week after initial intervention (Figure 5).

\section{Application of SSG to a broader community}

The SSG identified individuals at risk for stroke allowing

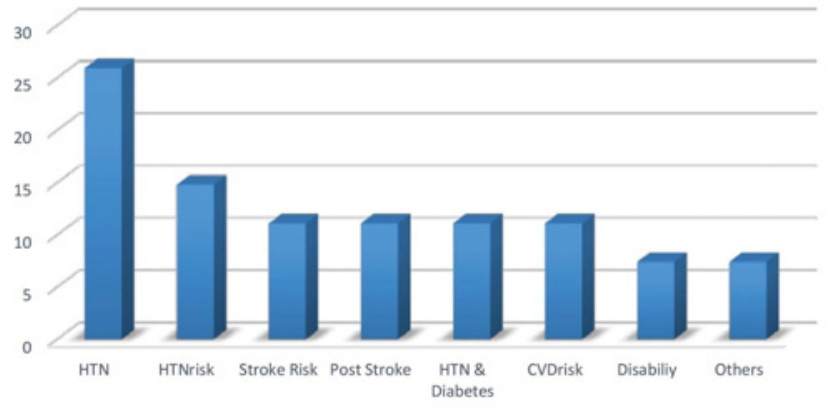

Figure 3: Percent of family members by illness and health risks $(n=72)$.
Table 1: Interventions provided to family.

\begin{tabular}{|c|c|c|}
\hline Type of intervention & Venue/ Methods & Providers \\
\hline Educational interventions & \multirow{4}{*}{ Home Health Care } & \multirow{4}{*}{$\begin{array}{c}\text { Faculty, } \\
\text { Nursing students, } \\
\text { Lay health volunteers }\end{array}$} \\
\hline Motivational interviews & & \\
\hline Stress management & & \\
\hline $\begin{array}{l}\text { Building capacity for } \\
\text { Hypertension and lipid } \\
\text { control }\end{array}$ & & \\
\hline Case management & $\begin{array}{l}\text { Home Health Care and } \\
\text { Primary Care Unit (PCU) }\end{array}$ & $\begin{array}{c}\text { Faculty, students, nurse } \\
\text { practitioners at local clinic }\end{array}$ \\
\hline Medical treatment & District Hospital, PCU & $\begin{array}{l}\text { Medical doctor, nurse } \\
\text { practitioners }\end{array}$ \\
\hline Community involvement & $\begin{array}{c}\text { Community and Village } \\
\text { hall (Grand round and } \\
\text { home visit) }\end{array}$ & $\begin{array}{c}\text { Faculty, students, nurse } \\
\text { practitioners at local clinic, } \\
\text { village leaders, } \\
\text { and health volunteers }\end{array}$ \\
\hline \multirow[t]{2}{*}{ Risk monitoring } & PCU & Nurses at local clinic \\
\hline & Community & $\begin{array}{c}\text { Village leaders, } \\
\text { and lay health volunteers }\end{array}$ \\
\hline
\end{tabular}

100
90
80
70
60
50
40
30
20
10
0

Case1

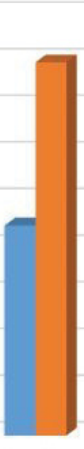

Case2

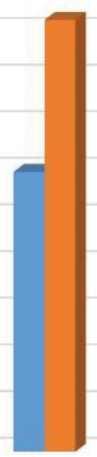

Case3

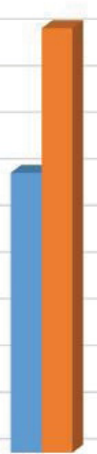

Case4

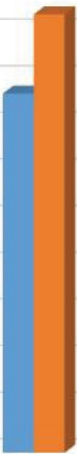

Case5

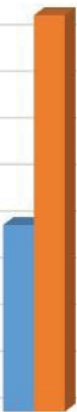

Case6

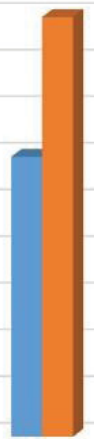

Case7
Before $n$ After

Figure 4: Comparison of knowledge scores at baseline and forth week after interventions.
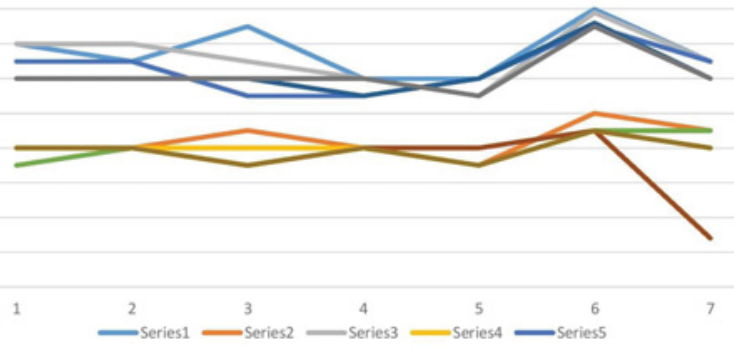

Figure 5: Changes in blood pressure over time.

nurses to focus attention on those most at risk and to implement proactive assessment, screening, and educational programs. Due to high prevalence of hypertension and rising cases of stroke, SSG was used to assess every family of patients with NCD for stroke risks. SSG findings were discussed with 
the community using a formal grand rounds and community forum approach. Tailored individual based, group-based, and family-based interventions were provided in a variety of other specific circumstances, including promoting hypertension control through behavioral changes and special approaches for the implementation of stroke and hypertension clinical guidelines in high-risk populations.

\section{Summary and Discussion}

The SSG was able to identify stroke risk of this family and suggest needs of further investigation on a broader level. There were no risks identified in the fourth generation which we propose is due to the young age and minimal exposure at this time. Therefore, programs aimed at prevention are warranted. Fluctuating blood pressure at the fifth week after initial intervention was due partly to receiving less frequent home visits.

Family genogram interviews were demonstrated to have good interinterviewer reliability [18]. Similar to applications of genogram on other health purposes, the SUT SSG could assist clinician to improve clients' health outcomes [1416,23 ]. Currently, available standard stroke screening tools such as ABCD2 and NIH stroke scale have poor to average positive predictive value and capture only pathogenic phase $[21,22,24,25]$. The SSG identified individuals at risk for stroke allowing nurses to focus attention on those most at risk and to implement proactive assessment, screening, and educational programs. Moreover, the SUT SSG has an advantage over the standard ABCD2 and NIH stroke scale due its ability to identify stroke risks at pre-pathogenic stage. Therefore, application of SSG is beneficial in identifying and reducing stroke risks.

\section{Recommendations}

The authors recommend clinicians, especially community health nurses, incorporate the SSG into all aspects of practice, from assessment for case finding to planning and implementing disease management strategies. Further study should investigate the predictive value of the SSG. Extending this SSG tool to large scale epidemiology studies is also recommended. As the SSG is low cost and user friendly, the authors recommend public health policy to incorporate the SSG into standard genogram currently in practice at primary care units to promote health care access, early detection, deliver interventions, and further prevent the burden of stroke.

\section{Acknowledgement}

Thanks to Pornsiri Wongthi, Pamika Ackaraprasertkul, Taksaporn Kangromklang, Nongluck Sandee, Umaporn Vachada, Juthathip Janphet, and Patcharida Sookserm former BSN students of Suranaree University of Technology, Nakhon Ratchasima, Thailand and Robert Flood, Stephanie Johnson, and Clare Kummant, former Nurse Practitioner students of University of Michigan School of Nursing, USA for their contribution of assessing, caring, monitoring, and evaluating for health of this at risk family. The authors acknowledge local PCU, village health volunteers, and local administrative office for their contribution on monitoring and continuing care.

\section{References}

1. World Health Organization (2011) Global status report on noncommunicable diseases 2010. Italy: World Health Organization. Link: https://goo.gl/Y6vXtc

2. Boutayeb A (2006) The double burden of communicable and noncommunicable diseases in developing countries. Trans R Sco Trop Med Hyg 100: 190-199. Link: https://goo.gl/xFjjxV

3. Kaufman ND, Chasombat S, Tanomsingh S, Rajataramya B, Potempa K (2011) Public health in Thailand: Emerging focus on non-communicable diseases. Int J Health Plann Manage 26: 197-212. Link: https://goo.gl/kxqenB

4. Dans A, Ng N, Varghese C, Tai ES, Firestone R, et al. (2011) The rise of chronic non-communicable diseases in southeast Asia: time for action. The Lancet 377: 680-689. Link: https://goo.gl/PUZKD2

5. Bundhamcharoen K, Odton P, Phulkerd S, Tangcharoensathien V (2011) Burden of disease in Thailand: changes in health gap between 1999 and 2004. BMC Public Health 11: 53. Link: https://goo.gl/ZYSqSt

6. Kaufman N, Rajataramya B, Tanomsingh S, Ronis D, Potempa K (2012) Nurse preparedness for the non-communicable disease escalation in Thailand: A cross-sectional survey of nurses. Nurs Health Sci 14: 32-37. Link: https://goo.gl/uzJxXB

7. Khonputsa P, Veerman JL, Vos TF, Aekplakorn W, Bertram M, et al. (2012) Joint prevalence and control of hypercholesterolemia and hypertension in Thailand: third national health examination survey. Asia Pac J Public Health 24: 185-194. Link: https://goo.gl/iXwxpD

8. Howteerakul N, Suwannapong N, Sittilerd R, Rawdaree P (2006) Health risk behaviours, awareness, treatment and control of hypertension among rural community people in Thailand. Asia Pac J Public Health 18: 3-9. Link: https://goo.gl/M35LyA

9. Ueshima H, Sekikawa A, Miura K, Turin TC, Takashima N, et al. (2008) Cardiovascular Disease and Risk Factors in Asia: A Selected Review. Circulation. 118: 2702-2709. Link: https://goo.gl/1L25yB

10. Fuster V, Kelly BF, Vedanthan R (2011) Global cardiovascular health: urgent need for an intersectoral approach. J Am Coll Cardiol. 58: 1208-1210. Link: https://goo.gl/3Z9VQE

11. Evans RL, Connis RT, Bishop DS, Hendricks RD, Haselkorn JK (1994) Stroke: A family dilemma. Disabil Rehabil 16: 110-118. Link: https://goo.gl/3AWMst

12. Anderson V, Gomes A, Greenham M, Hearps S, Gordon A, et al. (2014) Socia competence following pediatric stroke: contributions of brain insult and family environment. Soc Neurosci 9: 471-83. Link: https://goo.gl/tRqtAz

13. Cheng HY, Chair SY, Chau JP (2014) The effectiveness of psychosocial interventions for stroke family caregivers and stroke survivors: systematic review and meta-analysis. Patient Educ Couns 95: 30-44. Link: https://goo.gl/FdWqK6

14. Puskar K, Faan PH, Nerone M (1996) Genogram: A useful tool for nurse practitioners. J Psychiatr Ment Health Nurs 3: 55-60. Link: https://goo.gl/iPNMrk

15. Darwent KL, McInnes RJ, Swanson V (2016) The Infant Feeding Genogram: a tool for exploring family infant feeding history and identifying support needs. BMC Pregnancy and Childbirth. 16: 315. Link: https://goo.gl/18ozsJ

16. Dudley-Brown SL (2004) The genetic family history assessment in gastroenterology nursing practice. Gastroenterol Nurs 27: 107-110. Link: https://goo.gl/KpEF25

17. Hockley J (2000) Psychosocial aspects in palliative care: communicating with the patient and family. Acta Oncol 39: 905-910. Link: https://goo.gl/YXSNnU 
18. Platt LF, Skowron EA (2013) The family genogram interview reliability and validity of a new interview protocol. Fam J 21. Link: https://goo.gl/rzbcBe

19. Singha-Dong N (2015) Nursing Practicum of Community Health Manual. [Manual in Thai]. Suranaree Univerity of Technology: Suranaree Univerity of Technology, Institute of Nursing School of Community Health Nursing.

20. Singha-Dong N (2016) Huay Tai Community Improvement Program Report [in Thai]. Suranaree Univerity of Technology: Suranaree Univerity of Technology, Institute of Nursing School of Community Health Nursing.

21. Bhatt A, Jani V (2011) The ABCD and ABCD2 Scores and the Risk of Stroke following a TIA: A Narrative Review. ISRN Neurology 2011: 518621. Link: https://goo.gl/gxEMnw

22. Cheung CM, Fau TT, Hon SF, Au-Yeung M, Shiu KL, et al. (2008) Using the National Institutes of Health Stroke Scale (NIHSS) to predict the mortality and outcome of patients with intracerebral haemorrhage. Hong Kong Med $\mathrm{J}$ 14: 367-370. Link: https://goo.gl/gJyoCW
23. Kent-Wilkinson A (1999) Forensic family genogram. An assessment \& intervention tool. J Psychosoc Nurs Ment Health Serv 37: 52-56. Link: https://goo.gl/hqemrx

24. Ghia D, Thomas P, Cordato D, Epstein D, Beran RG, et al. (2012) Low positive predictive value of the $A B C D 2$ score in emergency department transient ischaemic attack diagnoses: the South Western Sydney transient ischaemic attack study. Intern Med J 42: 913-918. Link: https://goo.gl/Nnw74m

25. Adams HP Jr, del Zoppo G, Alberts MJ, Bhatt DL, Brass L, et al. (2007) Guidelines for the early management of adults with ischemic stroke: a guideline from the American Heart Association/American Stroke Association Stroke Council, Clinical Cardiology Council, Cardiovascular Radiology and Intervention Council, and the Atherosclerotic Peripheral Vascular Disease and Quality of Care Outcomes in Research Interdisciplinary Working Groups: the American Academy of Neurology affirms the value of this guideline as an educational tool for neurologists. Stroke 38: 1655-1711. Link: https://goo.gl/M1mknS

Copyright: (c) 2017 Singha-Dong N, et al. This is an open-access article distributed under the terms of the Creative Commons Attribution License, which permits unrestricted use, distribution, and reproduction in any medium, provided the original author and source are credited. 